\title{
ANALISIS TITIK IMPAS DAN KEUNTUNGAN USAHATANI KARET DI DESA TALANG PERAPAT KECAMATAN SELUMA BARAT KABUPATEN SELUMA
}

\author{
Sri Sugiarti
}

\begin{abstract}
This research was aimed at estimacy to break even point, level of profit and barganing position on the marketing system, was conducted village talang Perapat, in the subdistrict of Seluma Barat Seluma district. Break even point analysis which describe the ratio between revenue and fixed cost and profit was used. At a selling price for structure rubber bat of beginning the seventh years Rp 1300, break even point 5,24 for $\mathrm{Kg} / \mathrm{Ha} /$ year were lower than average fild productivitas. In this situation, the level of profit and berganing position in structur rubber bath bath enough hing to be profitable.
\end{abstract}

\section{PENDAHULUAN.}

Ekspor komoditas perkebunan indonesia sebagian besar masih dalam bentuk komoditas primer. Dalam rangka meningkatkan devisa negara , menjariang nilai tambah, memperkuat struktur ekspor, mengurangi resiko fluktuasi harga komoditas primer perkebunan dan mencegah penurunan nilai tukar serta antisipasi terhadap kejenuhan passar komoditas primer dimasa mendatang perlu pengolahan perkebunan. Salah satu perkebunan ekspor yang di tingkatkan dan perlu pengolahan.

Di propinsi bengkulu komoditas karet banyak diusahakan, mengingat topografi dataran sedang yang cocok uintuk di usahakan tanaman perkebunan karet. Pengelolaan kebun karet yang baik oleh petani dimaksudkan untuk menghasilkan produksi sehingga pada akhirnya petani mendapatkan keuntungan dan pendapatan yang tinggi. Upaya untuk mendapatkan keuntungan cepat dilakukan dengan menekan biaya produksi dan menignkatkan mutu pada tingkat harga jual tertentu. Dalam rangka meningkatkan keuntungan dapat di laksanakan meningkatkan produktivitas sehingga petani akan mempunyai daya saing yang kuat dalam pemasaran. Upaya ini penting mengingat fluktuasi harga di pasaran dunia sangat tajam (Sugiarto.1986).

Bila produktivitas dianggap telah cukup memadai maka jalan lain untuk memperkuat daya saing petani adalah memperbaiki mutu bahan olah karet. Hasil produksi karet yang didapatkan dipetani talang perapat adalah masih berbentuk dibakan / cetakan. Yang dijual langsung pada pembeli (toke) /pedagang pengumpul karet yang aqda didesa tersebut dan biasanya setiap 
minggu. Mutu karet dan harga jual merupakan dua faktor penting untuk menentukan tingkat keuntungan dan daya saing petani.

Harga jual sangat berpengaruh terhadap tingkat titik impas. Titik impas merupakan keadaan dimana nilai penjualan sama dengan biaya total. Oleh karena itu, mutu karet yang baik sangat penting untuk menjamin keuntungan petani sesuai dengan situasi pasar yang berlaku.Penulis mencoba menganalisis hubungan mutu karet dengan titik impas, tingkat keuntungan dan daya saing yang diperoleh petani dalam sistem pemasaran yang berlaku.

\section{METODE PENELITIAN}

Penentuan lokasi dilakukan dengan sengaja yaitu di Desa Talang Perapat Kecamatan Seluma Barat Kabupaten Seluma. Responden pada penelitian ini adalah petani yang melakukan kegiatan perkebunan karet, dimulai musim tanam 1993-2004 Jumlah sampel yang diambil 15 orang, dari populasi berjumlah 48 orang petani karet. Metode penetapan harga yang didasarkan permintaan pasar dan masih mempertimbangkan biaya adalah titik impas (kg/ha/tahun). Nilai Keuntungan di atas titik impas merupakan rasio penerimaan terhadap biaya tetap dan keuntungan (Rp/ha/tahun).Berikutnya daya saing berdasarkan jalur keuntungan merupakan rasio penerimaan terhadap penerimaan (\%).

\section{HASIL DAN PEMBAHASAN}

Hasil pengamatan menunjukan bahwa rata-rata produktivitas per tahun pada tahun ke $6 \mathrm{~s} / \mathrm{d}$ tahun 11, berada di atas titik impas (TI), dapat dilihat Tabel 1. Nilai titik impas (TI), dipengaruhi oleh perubahan harga jual, biaya tetap dan biaya variabel.penurunan NTI dipengaruhi oleh harga jual, dan penurunan biaya tetap, sedang kenaikan NTI kurang dipengaruhi oleh perubahan biaya variabel.

Tabel 1. Nilai Titik Impas Dan Nilai Titik Impas Karet Di Desa Talang Prapat Kecamatan Seluma

\begin{tabular}{|c|c|c|c|c|c|c|c|}
\hline \multirow[t]{2}{*}{ No. } & \multirow[t]{2}{*}{ Uraian } & \multicolumn{6}{|c|}{ Tahun Ke } \\
\hline & & $1 \mathrm{~s} / \mathrm{d} 6$ & 7 & 8 & 9 & 10 & 11 \\
\hline 1 & Biaya tetap (Rp/Tahun) & 36000 & 6000 & 6000 & 6000 & 6000 & 6000 \\
\hline 2 & $\begin{array}{l}\text { Biaya Variabel (Rp/ } \\
\text { tahun) }\end{array}$ & 1850862.27 & 262538 & 262538 & 262538 & 262538 & 262538.9 \\
\hline 3 & $\begin{array}{l}\text { Volume produksi } \\
\text { (Rp/kg) }\end{array}$ & 968.12 & 1687.67 & 1687.67 & 1687.6 & 1687.6 & 1687.67 \\
\hline 4 & Harga jual (Rp/kg) & 1100.00 & 1300.00 & 1700.0 & 2400.0 & 2800.0 & 3500.00 \\
\hline
\end{tabular}




\begin{tabular}{llrrrrrr}
5 & Titik impas (kg/ha) & 44.35 & 5.24 & 3.89 & 2.67 & 2.27 & 1.79 \\
6 & Nilai titik impas (Rp) & 4878.50 & 6812.00 & 6613.0 & 6408.0 & 6356.0 & 6265.0 \\
\hline
\end{tabular}

Sumber :

Perubahan harga jual dapat disebabkan oleh perubahan situasi pasar, perubahan imbalan terhadap nilai tanbah karena perubahan mutu karet cetakan ( bak) dan kebijaksanaan pemerintah. Perubahan biaya tetap dapat disebabkan adanya biaya investasi, biaya administrasi, biaya kredit dan lain lain. Perubahan biaya variabel dapat disebabkan oleh adanya kenaikan harga pembelihan bahan(pupuk, pertisida, asam cuka, tawas) dan volume penjualan. Nilai titik impas secara teoritis akan turun dengan kenaikan biaya variabel. Namu dalam hasi pengamatan menun jukan perubahan sangat kecil, karena kotribusi biaya variabel sangat kecil.

\section{Tingkat Keuntungan}

Petani akan mendapat keuntungan apabila harga jual karet dalam bentuk cetakan (bak) dapat dilihat Tabel I, mulai dapat untung tahun ke 7 yaitu 1300 00, -/Kg dan keuntungan yang diperoleh Rp. 1925432.08 per Ha per tahun. Tingkat keuntungan NTI dipengaruhi oleh perubahan harga jual, biaya tetap, biaya variabel dan volume penjualan. Secara umum dapat dinyatakan bahwa kenaikan harga jual, penurunan biaya tetap dan kenaikan volume penjualan bersifat menguntungkan petani dan begitu sebaliknya.

Perubahan akan terjadi dengan adanya perubahan harga dan volume penjualan, dapat dilihat tabel 2. namun demikian perubahan volume penjualan harus sesuai dengan tingkat produksi yang oktimal pada umur tanaman tertentu. Apabila diperhatikan pada tahun sadap ke 2 (tanaman ke 7 ) terdapat indikasi penyadapan yang berlebih,sehingga dalam jangka panjang dapat berpengaruh negatif pada kondisi tanaman. Pengaruh perubahan biaya tetap sifatnya nominal terhadap besarnya keuntungan.mengingat penurunan biaya tetap sangat menguntungkan maka penurunan berapa biaya tetap masih mungkin dilakukan antara lain dengan menurunkan paket kredit, (kebetulan pada daerah penelitian menggunakan perhitungan biaya riil seperti biaya penyusutan, modal sendiri tidak dihitung sebagai biaya tetap), meningkatkan produktifitas tenaga kerja, realokasi tenaga kerja pemungut hasil untuk kegiatan lain serta mengoktimalkan umur ekonomis tanaman.

\section{Jalur (Potensi) Keuntungan dan Daya saing}


Jalur keuntungan merupakan daerah dimana nilai penjualan telahmelampaui titik impas. Adanya jalur keuntungan yang cukup luas merupakan hal yang pentingbagi petani. Sebab jika jalur keuntungan tersebut sempit akan membahayakan kelangsungan usaha taninya (LPPH, 1982). Jalur keuntungan di daerah penelitian dapat dilihat Tabel 2.

Tabel 2 : Keuntungan, Jalur Keuntungan Dan Daya Saing Di Desa Talang Perapat Kecamatan Seluma Barat Kabupaten Seluma.

\begin{tabular}{|c|c|c|c|c|c|c|c|}
\hline \multirow[t]{2}{*}{ NO } & \multirow[t]{2}{*}{ Uraian } & \multicolumn{6}{|c|}{ Tahun Ke } \\
\hline & & $1 \mathrm{~s} / \mathrm{d} 6$ & 7 & 8 & 9 & 10 & 11 \\
\hline 1 & $\begin{array}{l}\text { Biaya total } \\
\text { tetap }(\mathrm{Rp} / \mathrm{Ha})\end{array}$ & 36000 & 6000 & 6000 & 6000 & 6000 & 6000 \\
\hline 2 & $\begin{array}{l}\text { Biaya Variabel } \\
(\mathrm{Rp} / \mathrm{Ha})\end{array}$ & 1850862.27 & 262538.92 & 262538 & 262538.9 & 262538.92 & 262538.9 \\
\hline 3 & $\begin{array}{l}\text { Biaya total } \\
(\mathrm{Rp} / \mathrm{Ha})\end{array}$ & 1886862.27 & 268538.92 & 268538 & 268538 & 268538.92 & 268538.9 \\
\hline 4 & $\begin{array}{l}\text { Penerimaan } \\
\text { (P) }(\mathrm{Rp} / \mathrm{Ha})\end{array}$ & 1064932.00 & 2193971 & 2869039 & 4050408 & 4725476 & 5906845 \\
\hline 5 & $\begin{array}{l}\text { Keuntungan } \\
\text { (K) (Rp/Ha) }\end{array}$ & -821930.27 & 1925432 & 2600600 & 3781689 & 4456937.1 & 5638306 \\
\hline 6 & $\begin{array}{l}\text { Jalur } \\
\text { keuntungan } \\
\text { (Rp/Ha) }\end{array}$ & 1113711.84 & 2187155 & 2862434 & 3536399 & 4719083.01 & 5900565 \\
\hline 7 & $\begin{array}{l}\text { Daya saing } \\
(\%)\end{array}$ & 100 & 99.69 & 99.97 & 78.50 & 99.87 & 99.89 \\
\hline
\end{tabular}

Mencapai jalur keuntungan terbesar yaitu 100 persen merupakan tujuan dari manajemen. Jalur keuntungan ini akan memberi gambaran daya saing petani dalam pasaran. Apabila dikaitkan dengan rantai pemasaran dari petani ke toke maka komposisi daya saing terbesar $78,5 \%$ untuk petani dan 21,5 persen untuk toke. Perubahan keuntungan yang meningkatkan jalur keuntungan dan daya saing meliputi kanaikan harga jual, volume penjualan, serta penurunan biaya tetap sedangkan menurunkan keuntungan dan daya saing meliputi penurunan harga jual, volume penjualan, serta kenaikan biaya tetap dan biaya variabel.

\section{KESIMPULAN}

Pada harga jual karet dalam bentuk bak dimulai harga Rp 1300.-diperoleh titik impas ratarata lebih rendah dari produktivitas yang dihasilkan petani. Titik impas rata-rata tersebut 10,03 $\mathrm{Kg} / \mathrm{Ha} /$ Tahun. Perubahan TI lebih peka terhadap penurunan harga jual dari pada kenaikan harga jual, sedangkan perubahan biaya tetap mengakibatkan perubahan titik impas bersifat proporsional 
dan perubahan biaya variabel mengakibatkan titik impas relatif tidak berubah, pada kondisi harga yang berlaku pada tahun ke tujuh petani sudah mendapatkan keuntungan. Jalur keuntungan dan daya saing cukup tinggi yang terbesar mencapai 78,5\%.

\section{DAFTAR PUSTAKA}

Lembaga Pendidikan dan Pembinaan Manajemen, 1982. Sistem Break Even Seri Manajemen no 6 LPPM

Ruzi Hadianto, 2005. Analisis Biaya dan Pendapatan Usahatani Karet di Desa Talang Perapat Kecamatan Seluma Barat Kabupaten Seluma Bengkulu.

Soehargdi Sigit,1976. Analisa Break Even. PAAP Fakultas Ekonomi UGM Yogyakarta.

Sugiarto, 1986. Simulasi Harga Pokok dan Harga Jual Terhadap Break Even Yield Di Perkebunan Karet Studi Kasus Di XVIII Kebun Getas Salatiga. 